\title{
Implementing Student Management for Children with Special Needs in Special Schools
}

\author{
Monadia Turrahmi ${ }^{1 \times}$, Abhanda Amra ${ }^{2}$ \\ Manajemen Pendidikan Islam, Institut Agama Islam Negeri Batusangkar, Indonesia ${ }^{1,2}$ \\ email: monadiaturrahmi@gmail.com¹ ${ }^{1}$,abhandaamra@iainbatusangkar.ac.id ${ }^{2}$
}

\begin{tabular}{ll}
\hline Article info & \multicolumn{1}{c}{ Abstract } \\
\hline ArticleHistory & This studyaims to describe and analyze the implementation of student management \\
Recieved: & for children with special needs in a special school. This study used the descriptive \\
$06 / 03 / 2021$ & qualitative method. Data were collected using three techniques namely \\
Accepted: & observation, interview, and documentation which involved the school principal, \\
$04 / 05 / 2021$ & vice principal, and teachers at SLBN 1 Lima Kaum Tanah Datar Regency as the \\
Published: & sources of data. The data were analyzed in three steps, they were data reduction, \\
$10 / 05 / 2021$ & display, and verification. Trustworthiness data was done by conducting \\
& triangulation. This study found that the implementation of student management for \\
& children with special needs was run well based on the established procedures. It \\
Corresponding author & was proven by the existence of student planning managements including needs \\
& analysis and school activities program construction; student coaching \\
& management including student discipline coaching through scouting activities and \\
& special services for the students; and student evaluation management through \\
& learning outcome and achievement of teachers and the students as well to optimize \\
& the student management.
\end{tabular}

Keywords: Student Management, Children With Special Needs, Special Schools

\begin{abstract}
Abstrak
Tujuan penelitian ini adalah untuk mendeskripsikan dan menganalisis proses implementasi manajemen kesiswaan bagi anak berkebutuhan khusus di sekolah luar biasa. Jenis penelitian menggunakan metode deskriptif kualitatif. Teknik pengumpulan data melalui observasi, wawancara, dan dokumentasi. Sumber data berasal dari kepala SLB, wakil kepala SLB dan para pendidik di Negeri 1 Lima Kaum Kabupaten Tanah Datar. Analisis data dalam penelitian melalui tiga tahapan yaitu reduksi data, penyajian data, dan penarikan kesimpulan. Uji keabsahan data penelitian dengan melakukan triangulasi. Hasil penelitian ditemukan bahwa implementasi manajemen kesiswaan bagi anak berkebutuhan sudah sesuai dengan prosedur yang telah ditetapkan dan berjalan dengan baik yang dibuktikan dengan adanya manajemen perencanaan kesiswaan berupa analisis kebutuhan dan penyusunan program kegiatan sekolah, dalam manajemen pembinaan kesiswaan terdapat pembinaan kedisiplinan peserta didik melalui kegiatan pramuka dan pemberian layanan khusus kepada peserta didik sesuai dengan disabilitas dan dalam manajemen evaluasi kesiswaan dilihat dari hasil belajar siswa dan juga dilihat dari prestasi yang diperoleh oleh pendidik dan siswa sehingga manajemen kesiswaan sudah berjalan optimal.
\end{abstract}

Kata Kunci: Manajemen Kesiswaan, Anak Berkebutuhan Khusus, SLB

JIES is licensed under a Creative Commons Atribution-Share Alike 4.0 Internasional Licence 


\section{PENDAHULUAN}

Anak berkebutuhan khusus di hadirkan oleh Tuhan ke dunia bukanlah sebagai produk gagal. Kekurangan baik secara kognitif maupun fisik tidak menghalangi potensipotensi yang ada pada diri siswa untuk berkarya dan berprestasi. Namun demikian, pemarginalan siswa untuk mendapatkan pendidikan yang layak dan baik masih di ditemukan (Haryono et al., 2015). Hal yang sama juga sampaikan oleh Pratiwi (2015) bahwa layanan pendidikan yang didapatkan oleh ABK masih memperoleh perbedaan perlakuan, hal tersebut terjadi karena pandangan masyarakat bahwa ABK harus berbeda perlakuan dengan anak normal agar tidak mengganggu pembelajaran.

Salah satu yang layanan pendidikan yang dibutuhkan oleh siswa ABK adalah bagaimana siswa mendapatkan manajemen kesiswaan di sekolah luar biasa. Layanan pendidikan berguna untuk mengembangkan bakat, minat dan kemampuan siswa semenjak dari proses penerimaan siswa sampai saat meninggalkan lembaga pendidikan. Layanan pendidikan yang tersedia bagai siswa ABK di Indonesia melalui tiga jalur yaitu, Sekolah Dasar Luar Biasa (SDLB), Sekolah Luar Biasa (SLB), dan Pendidikan Terpadu. (Sholawati, 2019). Oleh karena itu dalam mengakomodir layanan pendidikan tersebut diperlukan manajemen pengelolaan yang baik dalam satuan pendidikan yang sedang ditempuh oleh siswa ABK.

Manajemen kesiswaan merupakan segala yang berhubungan dengan pengelolaan mulai saat siswa diterima, memberikan pembinaan, sampai menyelesaikan pendidikan dengan menghadirkan suasana pembelajaran yang kondusif (Ariska, 2015; Wibowo, 2019). Manajemen kesiswaan merupakan salah satu isi dari manajemen pendidikan. Manajemen kesiswaan menempati posisi yang strategis karena pusat layanan pendidikan di dalam dan di luar institusi sekolah bersifat student centre (Suprapto, 2017). Seluruh kegiatan pendidikan, baik yang berkaitan dengan layanan, sumber daya keuangan, layanan pendukung akademik, sumber daya manusia, pengelolaan akademik, sumber daya keuangan, infrastruktur, dan hubungan sekolah dengan masyarakat, agar siswa dapat memperoleh layanan pendidikan yang andal. (Kristiawan et al., 2017, 2019; Santriati, 2019)

Hasil penelitian yang dilakukan oleh Amin et al., (2019), menyebutkan bahwa penerapan manajemen kesiswaan dapat meningkatkan prestasi non akademik siswa. Lebih lanjut beberapa penelitian menyebutkan bahwa sekolah menerapkan manajemen kesiswaan akan berdampak baik terhadap sekolah tersebut seperti dalam hal meningkatnya mutu organisasi yang terdapat disekolah tersebut dan dapat menjadikan sekolah tersebut menjadi lembaga pendidikan yang unggul dan berprestasi (Arnal et al., 2020; Hakim, 2016; Syahputra, 2020).

Implementasi manajemen kesiswaan merupakan sesuatu yang urgen yang menjadi perhatian oleh kepala sekolah beserta wakil kesiswaan bidang kesiswaan sehingga pelaksanaan kegiatan serta program di sekolah dapat menghasilkan beberapa prestasi di Sekolah SLB Negeri 1 Lima Kaum Kabupaten Tanah Datar. 
Dari permasalahan yang ada dan beberapa penelitian yang telah dikaji oleh peneliti sebelumnya bahwa manajemen kesiswaan merupakan hal penting dalam meningkatkan mutu sebuah lembaga pendidikan. Oleh karena itu peneliti mengkaji implementasi dari manajemen kesiswaan anak berkebutuhan khusus di sekolah luar biasa.

\section{METODE PENELITIAN}

Penelitian mengunakan pendekatan kualitatif dengan deskriptif, untuk menggambarkan kondisi subjek penelitian pada saat penelitian dilaksanakan. Data yang didapatkan yakni hasil wawancara, hasil pengamatan, analisis dokumen, ditata peneliti di lokus penelitian, tidak di tuangkan dalam bentuk dan angka-angka. Lokasi yang menjadi tempat penelitian yaitu di SLB Negeri 1 Lima Kaum Kabupaten Tanah Datar. Data-data primer diperoleh dari sumber primer melalui wawancara dengan kepala sekolah, wakil kepala dan para guru kelas.

Teknik pengumpulan data berupa metode wawancara (Interview), observasi partisipasi (Participan Observation) dan dokumentasi. Analisis data yang diterapkan menggunakan reduksi data, paparan atau penyajian data dan penarikan kesimpulan. Uji keabsahan data penelitian dengan melakukan triangulasi.

\section{HASIL DAN PEMBAHASAN}

Dalam implementasi manajemen kesiswaan anak berkebutuhan khusus di SLB Negeri 1 Lima Kaum kepala sekolah beserta wakil telah melakukan implementasi manajemen kesiswaaan ABK dengan baik dibuktikan dengan kegiatan manajemen perencanaan, manajemen pembinaan serta manajemen evaluasi kesiswaan ABK. Berikut adalah bentuk implementasi manajemen kesiswaan yang dilakukan di SLB Negeri 1 Lima Kaum:

\section{Manajemen Perencanaan Kesiswaan Anak Berkebutuhan Khusus di SLB Negeri Lima Kaum Kabupaten Tanah Datar}

Proses manajemen kesiswaan memiliki beberapa tahapan yang harus dilalui seperti perencanaan. Perencanaan adalah kegiatan awal dilakukan dalam manajemen kesiswaan perencanaan penerimaan siswa baru, jumlah putus sekolah, kelulusan, dan kepindahan. Untuk perencanaan peserta didik berkaitan langsung dengan aktivitas penerimaan dan pendokumentasian dari data pribadi siswa. Temuan hasil penelitian di SLB Negeri 1 Lima Kaum Tanah Datar menunjukkan bahwa kepala sekolah beserta tenaga pendidik dan kependidikan sudah melakukan perencanaan dengan baik, segala bentuk perencanaan yang terdapat dalam hasil penelitian intinya telah dijalankan seuai prosedur. Hasil penelitian yang peneliti lakukan di SLB Negeri 1 Lima Kaum kepala sekolah, tenaga pendidik dan kependidikan sudah melakukan langkah sesuai dengan teori tersebut hanya saja cara dan pola yang dilakukan sedikit berbeda dengan sekolah pada umumnya, berikut adalah perencanaan manajemen kesiswaan yang dilakukan oleh SLB Negeri 1 Lima Kaum: 
a. Analisis kebutuhan peserta didik

Penerimaan siswa baru adalah langkah awal dalam manajemen kesiswaan dengan adanya penerimaan siswa baru di SLB Negeri 1 Lima Kaum, sekolah ini melakukan analisis kebutuhan dengan cara menghitung daya tampung yang didasarkan pada jumlah sarana dan prasarana, jumlah guru, dan melihat jarak tempat tinggal peserta didik dari rumah ke sekolah dan juga membangun komunikasi dengan warga sekolah, mempersiapkan perangkat administrasi yang diperlukan untuk penerimaan peserta didik baru lalu melakukan koordinasi dengan tenaga ahli yang akan memeriksa kelainan yang di alami oleh anak seperti psikolog, dokter THT dan lain-lain. Sekolah juga tidak membatasi jumlah penerimaan siswa karena memang tidak banyak siswa ABK yang mendaftar, setiap tahunnya yang mendaftar hanya berkisar 15-20 orang.

Jadi dapat disimpulkan bahwa analisis kebutuhan siswa dilaksanakan di SLB Negeri 1 Lima Kaum dengan membuat rencana penerimaan siswa baru dan program sekolah, mengenai program di sekolah telah diatur. program pengembangan manajemen siswa secara umum tertuang dalam Perdirjen Nomor: 10/D/KR/2017 tentang struktur kurikulum 2013 pendidikan khusus, dan lebih khususnya ditambah dengan program keterampilan pilihan yang memungkinkan siswa kelak dapat hidup mandiri baik secara sosial ataupun ekonomi.

\section{b. Rekrutmen peserta didik}

Rekrutmen peserta didik pada hakikatnya proses pencarian, menentukan peserta didik di lembaga sekolah yang bersangkutan melihat dari hasil penelitian yang peneliti lakukan di SLB Negeri 1 Lima Kaum telah melaksanakan rekrutmen peserta didik mengikuti teori yang ada seperti membentuk panitia, tetapi di SLB disebut dengan tim penerima peserta didik baru, pemasangan pengumuman juga sudah dilakukan dengan membuat spanduk serta membuat informasi di sosial media yang dimiliki oleh SLB. Selanjutnya untuk pendaftaran siswa di SLB Negeri 1 Lima Kaum tidak melakukan tes tulis ataupun melalui nilai, siswa hanya melakukan tes wawancara. Wawancara dilakukan oleh peserta didik dan orang tua dengan memberikan beberapa pertanyaan. Proses tersebut dikenal dengan asesmen peserta didik, jadi peserta didik yang akan mendaftar ke SLB mereka terlebih dahulu melakukan cek ketunaan dirumah sakit atau psikolog agar ketika mendaftar diketahui ketunaan/kelainan yang siswa alami sehingga memudahkan tim penerima siswa baru di SLB menempatkan siswa tersebut sesuai dengan ketunaannya. Sesuai dengan hasil wawancara peneliti dengan beberapa narasumber mengenai implementasi manajemen kesiswaan anak berkebutuhan khusus di SLB Negeri 1 Lima Kaum diketahui bahwa proses rekrutmen peserta didik telah dilakukan dan berjalan lancar karena seluruh pihak sekolah berpartisipasi dalam setiap kegiatan yang ada di sekolah.

c. Seleksi peserta didik

Seleksi peserta didik merupakan kegiatan memilih calon siswa yang akan diterima menjadi peserta didik di satuan pendidikan sesuai dengan prosedur yang berlaku. Adapun teknis seleksinya sebagai berikut: a) Melalui tes dan ujian (tes keterampilan, tes jasmani, tes psikotes, tes kesehatan, tes akademis, atau tes akademis); b) Melalui penelusuran bakat 
kemampuan, biasanya berdasarkan pada prestasi yang diraih calon peserta didik dalam bidang olahraga atau kesenian; c) Berdasarkan nilai STTB atau nilai UAN (Badrudin, 2014:37). Berdasarkan hasil wawancara dengan beberapa narasumber di SLBN ada dilakukan seleksi siswa namun berbeda dengan seleksi sekolah pada umumnya, bukan tanpa alasan berbeda tahap seleksinya. Seleksi peserta didik di SLB dilakukan hanya dengan tes psikotes, tes jasmani dan tes kesehatan dengan bentuk asesmen peserta didik. Setiap tahun jumlah siswa yang mendaftar hanya sedikit dan tidak melebihi kapasitas atau daya tampung sekolah. jadi mereka hanya melakukan tes dan cek fisik di rumah sakit dan psikolog setelah itu bisa langsung mendaftar ke SLB Negeri 1 lima Kaum dilakukan asesmen dan mereka dimasukkan ke kelas yang sesuai dengan ketunaan mereka.

d. Orientasi peserta didik baru

Orientasi peserta didik baru yang dilakukan di SLBN melakukan orientasi yang berbeda dengan sekolah reguler seperti di sekolah reguler biasanya melakukan orientasi yang disebut dengan istilah MOS (Masa Orientasi Sekolah). Sedangkan di SLB siswa baru akan langsung dilayani oleh guru kelas dan guru kelaslah yang bertugas mengenalkan lingkungan sekolah kepada siswa baru baik lingkungan fisik atau lingkungan sosial namun ada juga saat siswa dikumpulkan di suatu ruangan dan diberikan penjelasan tentang lingkungan fisik dan lingkungan sosial sekolah, namun guru kelas juga diberi wewenang untuk mengenalkan lingkungan sekolah kepada siswa baik tentang pelayanan, pelajaran dan lain-lain dikarenakan jumlah siswa yang sedikit jadi tidak akan sulit bagi guru kelas melakukan pengenalan lingkungan sekolah terhadap siswa SLB.

e. Penempatan peserta didik (pembagian kelas)

Penempatan peserta didik di SLB dilakukan ketika penerimaan siswa baru, di SLB terdiri dari 3 tingkatan sekolah yaitu SDLB, SMPLB, SMALB yang di pimpin oleh satu kepala sekolah. Dari tingkatan itu juga dibagi jadi beberapa bagian ketunaannya yaitu tunadaksa, tunanetra, tunarungu, tunagrahita dan autis, jadi dapat disimpulkan siswa dikelompokkan berdasarkan ketunaan yang mereka miliki dan juga disesuaikan dengan umur siswa tersebut. Dengan demikian SLB Negeri 1 Lima Kaum sudah melakukan penempatan peserta dengan baik.

f. Pencatatan dan pelaporan peserta didik

Di SLB Negeri Lima Kaum dilakukan pencatatan dan pelaporan peserta dilakukan oleh wakil kesiswaan sekolah adalah pencatatan dan pelaporan peserta didik dengan membuat beberapa data dan mengisi buku seperti buku induk siswa, buku klaper, daftar presensi, daftar catatan pribadi peserta didik dan ada juga tenaga operator DAPODIK yang terus memperbarui data siswa per semester untuk setiap tahunnya jadi ini berjalan lancar di SLB Negeri Lima Kaum serta guru kelas juga selalu memberikan penilaian terhadap hasil belajar siswa SLB Negeri 1 Lima Kaum. Berdasarkan hal tersebut perencanaan yang dilakukan oleh SLB sudah dilakukan dengan baik meski ada sedikit perbedaan yaitu seperti seleksi peserta didik, hal tersebut berbeda karena hal tersebut memang seharusnya dilakukan dengan cara yang di lakukan oleh SLB dan sesuai untuk anak berkebutuhan khusus. Mereka yang mendaftar memiliki ketunaan yang sangat 
berbeda dengan anak normal lainnya. Sehingga menurut peneliti yang dilakukan kepala sekolah beserta tenaga pendidik dan kependidikan sudah baik dan mengikuti proses yang sesuai dengan teori yang ada.

Penelitian ini relevan dengan ajian sebelumnya yang telah melakukan penelitian bagaimana manajemen sekolah yang terdapat pada sekolah inklusi. Hasil penemuan bahwa dalam sekolah inklusi menerapkan manajemen kesiswaan melalui pelaksanaan PPDB secara bersamaan, siswa berada dalam satu kelas dan dikelompokkan dengan kemampuan akademik, kecerdasan, dan kebutuhan khusus yang sama. Pembinaan kesiswaan dengan program pembiasaan, ekstrakurikuler, dan kegiatan insidental, dan wajib adanya guru pendamping bagi siswa ABK (Hufron \& Imron, 2016).

\section{Manajemen Pembinaan Kesiswaan Anak Berkebutuhan Khusus di SLB Negeri 1 Lima Kaum}

Kepala sekolah dan wakil kesiswaan telah melakukan pembinaan terhadap siswa dengan baik hal ini berdasarkan wawancara yang peneliti lakukan, kepala sekolah dan guru memberikan pelayanan ekstra kepada anak berkebutuhan khusus, mereka dilayani secara individual dan disesuaikan dengan ketunaan mereka. Seperti halnya anak tunagrahita diberikan pelajaran sampai anak tersebut paham akan pelajarannya, anak tunagrahita merupakan anak-anak yang mengalami lemah daya tangkap terhadap pelajaran jadi terkadang guru harus mengulang beberapa kali sampai siswa tersebut mengerti. Di samping layanan khusus SLB Negeri 1 Lima Kaum juga melakukan pembinaan siswa melalui kegiatan ekstrakurikuler seperti pramuka, pramuka adalah kegiatan ekstra yang dilakukan di sekolah. Dalam kegiatan kepramukaan ini siswa akan dilatih untuk disiplin, berani dan percaya diri dalam hidupnya. Kegiatan pramuka di SLB Negeri 1 Lima Kaum aktif di laksanakan dan melakukan latihan sekali seminggu, pembina pramuka di SLB sendiri adalah guru SLB yang memiliki kemampuan di bidang kepramukaan.

Selain pelatihan kepramukaan, program lain yang di rancang seperti program keterampilan juga dilakukan untuk membina siswa agar memiliki kemampuan berwirausaha dan di harapkan setelah menyelesaikan pendidikan di SLB Negeri 1 Lima Kaum dapat membuka lapangan pekerjaan atau membuka usaha untuk keberlangsungan hidup mereka. Siswa SLB Negeri 1 Lima Kaum telah ada yang membuka usaha sendiri seperti usaha membuat desain gelas keramik yang telah di jual di pasaran dan menghasilkan uang, ada juga salah seorang siswa yang membuka usaha cetak batu batako yang hasilnya siswa tersebut bisa membiayai kakaknya yang sedang kuliah di universitas negeri, berdasarkan hal tersebut peneliti melihat bahwa pembinaan di SLB Negeri 1 Lima Kaum telah di laksanakan dengan baik dan berefek positif untuk perkembangan siswa berkebutuhan khusus.

Hasil penelitian oleh Kurniawati (2014), upaya peningkatan keberhasilan siswa dapat dilakukan dengan manajemen kesiswaan melalui pembinaan dan pengembangan oleh pihak manajemen sekolah dengan menyediakan infrastruktur yang mampu 
mendukung minat dan bakat seluruh siswa. Penelitian lain juga menyebutkan bahwa pembinaan merupakan salah satu strategi dalam mengembangkan bakat-bakat yang terdapat dalam diri siswa ABK melalui kegiatan ekstrakurikuler dan lain sebagainya (Rochmah \& Suwanda, 2019).

\section{Manajemen Evaluasi Kesiswaan Anak Berkebutuhan Khusus di SLB Negeri Lima Kaum}

Implementasi di SLB Negeri 1 Lima Kaum, sekolah telah melaksanakan evaluasi dengan baik. Hal tersebut dari hasil wawancara dengan beberapa narasumber kepala sekolah, wakil kesiswaan serta guru yang mengajar SLB Negeri 1 Lima Kaum diperoleh informasi bahwa evaluasi yang dilakukan di sekolah melalui kegiatan-kegiatan belajar peserta didik juga melalui ujian tengah semester dan ujian semester sama dengan sekolah reguler, ujiannya tertulis. Ujian yang dilakukan disesuaikan dengan kondisi si anak kalau dia sudah pandai membaca dan menulis dia akan mengikuti ujian tertulis tapi jika belum bisa membaca dia akan melakukan ujian dalam bentuk lain seperti melalui perkenalan benda-benda, angka, huruf atau bisa juga guru membacakan pertanyaan siswa menjawab pertanyaan tersebut, cara lain juga dengan menggunakan media digital seperti melalui film dan lain-lain. Dengan demikian evaluasi peserta didik melalui kegiatan belajar siswa telah dilakukan di SLB Negeri 1 Lima Kaum.

Hasil penelitian ini sejalan dengan penelitian yang dilakukan oleh (Aliyyah et al., 2019), menyebutkan bahwa manajemen evaluasi pembelajaran merupakan cara memberikan ulasan terhadap proses pelaksanaan yang telah berjalan dan hasil penilaian dari pembelajaran siswa.

\section{KESIMPULAN}

Implementasi manajemen kesiswaan anak berkebutuhan khusus telah dilakukan dan diimplementasikan dengan baik oleh kepala sekolah, wakil kesiswaan serta majelis guru sesuai dengan prosedur yang telah ditetapkan. Implementasi kesiswaan dilakukan untuk menunjang keberhasilan penjaminan mutu di suatu lembaga pendidikan melalui aspek manajemen perencanaan kesiswaan, pembinaan kesiswaan, dan evaluasi kesiswaan. Dengan mengimplementasikan manajemen kesiswaan tersebut maka akan mengakomodir minat dan bakat dengan mengembangkan potensi yang terdapat pada diri siswa. Temuan ini menjadi masukan bagi pemangku kebijakan pada satuan pendidikan khususnya Sekolah Luar Biasa (SLB) dalam menunjang potensi yang terdapat pada anak berkebutuhan khusus agar dapat menjamin mutu pendidikan yang diberikan kepada siswa.

\section{DAFTAR PUSTAKA}

Aliyyah, R. R., Widyasari, W., Mulyadi, D., Ikhwan, S., \& Prananosa, A. G. (2019). Manajemen Kesiswaan Pada Sekolah Dasar. Didaktika Tauhidi: Jurnal Pendidikan Guru Sekolah Dasar, 6(1), 29. https://doi.org/10.30997/dt.v6i1.1355 
Amin, M., Larasati, S. S., \& Fathurrochman, I. (2019). Implementasi Manajemen Kesiswaan Dalam Meningkatkan Prestasi Non Akademik Di Smp Kreatif 'Aisyiyah $\begin{array}{lllll}\text { Rejang Lebong. } & \text { Jurnal }\end{array}$ https://doi.org/10.47783/literasiologi.v1i1.11

Ariska, R. S. (2015). Manajemen kesiswaan. Manajer Pendidikan, 9(6). https://doi.org/10.31227/osf.io/ytzsq

Arnal, F. M., Fitria, H., \& Martha, A. (2020). Manajemen Kesiswaan Dalam Meningkatkan Mutu Organisasi. Pendidikan Tambusai, 4(2), 1820-1827.

Ely Kurniawati, E. R. (2014). Manajemen Kesiswaan Di SMA Negeri Mojoagung Jombang. Inspirasi Manajemen Pendidikan, 4(4), 207-213.

Hakim, M. N. (2016). Implementasi Manajemen Berbasis Sekolah Dalam Mewujudkan Sekolah Islam Unggulan. Nidhomul Haq : Jurnal Manajemen Pendidikan Islam, 1(2), Nidhomul Haq: Jurnal Manajemen Pendidikan Islam,. https://doi.org/https://doi.org/10.31538/ndh.v1i2.7

Haryono, Syaifudin, A., \& Widiastuti, S. (2015). Evaluasi Pendidikan Inklusif Bagi Anak Berkebutuhan Khusus (ABK) Di Provinsi Jawa Tengah. Jurnal Penelitian Pendidikan Unnes, 32(2), 124205. https://doi.org/10.15294/jpp.v32i2.5057

Hufron, A., \& Imron, A. (2016). Manajemen Kesiswaan Pada Sekolah Inklusi. Jurnal Pendidikan Humaniora, 4(2), 95-105. http://journal.um.ac.id/index.php/jph

Kristiawan, M., Safitri, D., \& Lestari, R. (2017). Manajemen Pendidikan. Deepublish.

Kristiawan, M., Yuniarsih, Y., \& Fitria, H. (2019). Supervisi Pendidikan. Alfabeta.

Pratiwi, J. C. (2015). Sekolah Inklusi Untuk Anak Berkebutuhan Khusus: Tanggapan Terhadap Tantangan Kedepannya. Prosiding Ilmu Pendidikan, 1(2).

Rochmah, N. A., \& Suwanda, I. M. (2019). Pembentukkan Karakter Disiplin Peserta Didik Berkebutuhan Khusus Melalui Kegiatan Ekstrakurikuler Pramuka di SMP Negeri 4 Sidoarjo. Kajian Moral Dan Kewarganegaraan, 7(2).

Santriati, M. (2019). Manajemen Kesiswaan. Manajemen Pendidikan, 13(3), 281-292. https://doi.org/10.31227/osf.io/vp785

Sholawati, S. A. (2019). Manajemen Pembelajaran Pendidikan Inklusi Pada Anak Berkebutuhan Khusus Di SD Kalirungkut-1 Surabaya. Abdau: Jurnal Pendidikan Madrasah Ibtidaiyah, 2(1), 39-60. https://doi.org/10.36768/abdau.v2i1.24

Suprapto, R. (2017). Pengaruh Manajemen Kesiswaan Terhadap Hasil Belajar Mata Pelajaran SKI Siswa Kelas VIII E MTsN Sambirejo Banyuwangi Tahun Pelajaran 2016/2017. Jurnal Darussalam: Jurnal Pendidikan, Komunikasi Dan Pemikiran Hukum Islam, 9(1), 176. https://doi.org/10.30739/darussalam.v9i1.124

Syahputra, M. R. (2020). Implementasi Manajemen Kesiswaan Di MTS Negeri 3 Medan Muhammad Rizki Syahputra. Education Achievment: Journal of Science and 
Research, 1(1), 1-7.

Wibowo, A. (2019). Integrasi Manajemen Kesiswaan Pendidikan Formal Dan Non Formal Di Pondok Pesantren An-Nawawi Berjan Purworejo. Jurnal Isema : Islamic Educational Management, 4(2), 221-228. https://doi.org/10.15575/isema.v4i2.6967 